\title{
O FUNCIONAMENTO DA IDEOLOGIA NO PROJETO DE LEI ESCOLA SEM PARTIDO: UMA LEITURA DE PRÁTICAS DISCURSIVAS DE INTOLERÂNCIA
}

\author{
Janaina Cardoso Brum ${ }^{32}$ \\ Jenifer Dias ${ }^{33}$
}

RESUMO: Em 2016, a proposta de Projeto de Lei intitulada Escola sem Partido foi apresentada em âmbito nacional no Brasil. Apesar de não aprovada em âmbito nacional, essa proposta circulou em estados e municípios, sendo referendada em alguns casos. O projeto visa coibir manifestações consideradas políticas e ideológicas por parte dos professores em sala de aula, a fim de não influenciar as escolhas políticas e morais dos estudantes. No presente trabalho, a partir do aparato teórico da Análise de Discurso fundada por Michel Pêcheux, analisamos um trecho do projeto confrontado com um trecho de uma paródia musical que figura no site de campanha do Movimento Escola sem Partido. Nossa hipótese inicial é a de que a designação "ideologia" presente no projeto é determinada em outro espaço, o do material de divulgação do PL.

Palavras-chave: Escola sem partido; ideologia; práticas discursivas de intolerância.

RESUMEN: En 2016, la propuesta de Proyecto de Ley titulada Escola sem partido fue presentada a nivel nacional en Brasil. A pesar de no aprobada en el país, esa propuesta circuló en estados y municipios, siendo aprobada en algunos casos. El proyecto pretende cohibir manifestaciones consideradas políticas e ideológicas por parte de los profesores en el aula, a fin de no influir en las elecciones políticas y morales de los estudiantes. En el presente trabajo, a partir del aparato teórico del Análisis de

${ }^{32}$ Professora do Centro de Letras e Comunicação da Universidade Federal de Pelotas e membro do Laboratório de Estudos em Análise de Discurso (LEADUFPel). Doutora em Letras pela Universidade Católica de Pelotas.

${ }^{33}$ Graduanda em Letras - Português e Literaturas pela Universidade Federal de Pelotas e membro do Laboratório de Estudos em Análise de Discurso (LEADUFPel). 
Discurso fundada por Michel Pêcheux, analizamos un trecho del proyecto enfrentado con un trecho de una parodia musical que figura en el sitio de campaña del Movimento Escola sem Partido. Nuestra hipótesis inicial es que la designación "ideología" presente en el proyecto se determina en otro espacio, el del material de divulgación del PL.

Palabras clave: Escola sem Partido; ideología; prácticas discursivas de intolerância.

\section{Considerações Iniciais}

Recentemente, no Brasil, especialmente após o impeachment de Dilma Rousseff em 2016, vimos enfrentando uma série de mudanças legislativas que repercutem diretamente em nosso sistema de proteção social. Entre diversas propostas que visam, em última análise, diminuir a participação do Estado na sociedade brasileira, está o Projeto de Lei Escola sem Partido (PL No. 193). Esse projeto foi apresentado em maio de 2016 em âmbito nacional e, também, nos âmbitos estaduais e municipais. Nos contextos municipais, o projeto já foi aprovado em diversas cidades, demonstrando o fortalecimento da proposta.

Dentre os municípios que propuseram o projeto de lei está Pelotas. No município, o Escola Sem Partido foi proposto pelos vereadores Enéias Clarindo (PSDB) e Fabrício Tavares (PSD), apoiados pelo Movimento Brasil Livre, sendo protocolado sem debates em 15 agosto de 2017. No entanto, as bancadas do PSOL, PT e PDT promoveram uma audiência pública ordinária em 23 de agosto de 2017 (5191/2017), com a presença de mais de 400 pessoas, sendo aprovada unanimemente uma moção contra o projeto. Após a pressão popular, os vereadores proponentes solicitaram, em 31 de agosto, o arquivamento junto à Comissão de Constituição e Justiça da Câmara de Vereadores de Pelotas.

O Projeto de Lei tem como escopo a proibição de alguns temas, como política, gênero e relações étnico-raciais, no sistema de ensino. Sob o argumento de que esses temas têm caráter "ideológico", o texto propõe que sejam proibidas aos professores atitudes que possam "influenciar" a formação política e ideológica dos estudantes, tais como: expressar sua opinião política, retratar em sala de aula uma matriz religiosa que não esteja de acordo com a convicção moral dos pais dos alunos, informar sobre atos de mobilização social ou até mesmo permitir que os alunos o façam. 
Em Análise de Discurso, dizemos que não há discurso sem ideologia. Estamos, então, lidando com saberes sobre ideologia que respondem a determinações históricas diversas. Se, por um lado, temos o conceito de ideologia ancorado na teoria althusseriana e na Análise de Discurso fundada por Michel Pêcheux, por outro, temos o termo "ideologia" que figura no projeto marcado como uma evidência, como algo desde sempre dado, algo que não precisa ser conceituado, já que é da ordem do que todo mundo sabe. Partindo da opacidade que a designação ${ }^{34}$ apresenta no Escola sem Partido, temos, no presente artigo, o objetivo de analisar como o projeto institui-se como uma zona de embate ideológico em torno da própria designação "ideologia". Partindo dos pressupostos teóricos da Análise do discurso (AD), recorremos, para a análise, a dois dos três elementos operacionais que Ernst-Pereira (2009) descreve: a falta, o excesso e o estranhamento. Vamos nos centrar, neste artigo, no estranhamento e especialmente na falta.

Dessa forma, procuramos destacar como filiações ideológicas que sustentam o Escola sem Partido materializam-se na língua, uma vez que a falta de determinadas palavras, bem como o estranhamento causado por alguns termos são, na verdade, índices de saberes de dadas formações discursivas às quais o sujeito filia-se. A impossível "neutralidade" ideológica em sala de aula - ou em qualquer outro espaço de discursividade - almejada pelo projeto é, assim, efeito de discurso e, como tal, trabalho da ideologia. Se, para Althusser (1985), todo indivíduo é interpelado ideologicamente e cada aparelho, seja jurídico ou escolar, articula-se aos outros para reproduzir as relações de produção na sociedade capitalista, para além da reflexão e análises do projeto propriamente dito, é preciso recorrer às suas condições de produção, pois trabalham diretamente na produção das evidências e, consequentemente, nos efeitos de sentido que o projeto faz ressoar.

\section{Algumas observações sobre Ideologia}

Louis Althusser (1985) concebe a Ideologia como um mecanismo a-histórico de produção dos sujeitos. Para tanto, elabora o conceito de interpelação ideológica, processo que funciona de modo a tornar sujeitos os

\footnotetext{
${ }^{34}$ Partimos da noção de “designação” tal como concebida por Guimarães (2005), ou seja, como significação própria das relações simbólicas afetadas pela história e, portanto, pela ideologia.
} 
indivíduos, ou seja, ao interpelá-los, produ-los no interior do que chama de assujeitamento ideológico. Dessa forma, concebemos o sujeito a partir de sua sujeição ao mecanismo da Ideologia, de sorte que, ao conceber-se livre, aliena-se na rede de evidências que a Ideologia produz. A evidência primeira dessa rede é a da "liberdade", por isso dizemos, a partir de Althusser e Pêcheux, que o sujeito assujeita-se livremente à Ideologia, esse mecanismo que se especifica por ser sem história e sem sujeito.

O funcionamento desse mecanismo dá-se a partir dos Aparelhos Ideológicos de Estado (Cf. Althusser, 1985), os quais, por sua vez, encarnam as ideologias particulares, especificamente a ideologia dominante, que, no sistema capitalista, é a ideologia do modo de produção capitalista. Sem que a dominância de uma classe sobre outra no caso da formação social capitalista, da burguesa sobre o proletariado seja visível ao sujeito, este se acredita livre, fonte, origem e controlador do seu dizer (PÊCHEUX, 1988). Eis a eficácia do funcionamento ideológico na formação social capitalista: sob a aparência de liberdade, o sujeito, investido de sua autonomia ilusória, é o próprio agente de sua alienação.

Essa tese fundamental de Althusser é retomada por Michel Pêcheux em suas obras principais. Contudo, como é característico de Pêcheux, não resta inalterada no decorrer das três fases da Análise de Discurso. Na terceira fase da $\mathrm{AD}$, Pêcheux faz um apelo à Psicanálise e centra seus esforços na caracterização do "ritual" ideológico como falho. É a partir de Jacques Lacan que Pêcheux empreende essa autocrítica e, por isso, a questão do inconsciente torna-se central. Em seu célebre texto de retificação Só há causa daquilo que falha ou o inverno político francês: início de uma retificação, Pêcheux (1988) faz intervir no Marxismo, especificamente no conceito de ideologia, a Psicanálise - relação esta já antevista por Althusser (1985) e pelo próprio Pêcheux -, através do conceito de inconsciente. $\mathrm{O}$ sujeito como causa de si do althusserianismo passa a ser pensado diretamente em sua relação com o desejo - o desejo inconsciente - e, por esse motivo, não pode mais figurar como mero autômato que se identifica a uma dada rede de saberes sem a questionar, sem resistir a ela de alguma forma.

A "repetição eterna" a que estava fadado, segundo alguns críticos, o sujeito althusseriano é, então, questionada por Pêcheux a ponto de confrontá-la com o conceito de resistência. Ainda que, em Les verités de la Palice, já acrescentasse o termo "transformação" à reprodução das relações de produção, tal como concebida por Althusser, Pêcheux, em seu 
movimento retificador, vai mais longe e leva às últimas consequências sua concepção de resistência no ritual ideológico:

(...) o non-sens do inconsciente, em que a interpelação encontra onde se agarrar, nunca é inteiramente recoberto nem obstruído pela evidência do sujeito-centro-sentido que é seu produto, porque o tempo da produção e o do produto não são sucessivos como para o mito platônico, mas estão inscritos na simultaneidade de um batimento, de uma 'pulsação' pela qual o non-sens inconsciente não para de voltar no sujeito e no sentido que nele pretende se instalar" (PÊCHEUX, 1988, p. 300).

Em outras palavras, Pêcheux reconhece um erro: o de não ter percebido que produção e produto - assujeitamento e sujeito - não podem ser pensados como sucessivos, pois se dão em um batimento simultâneo e, por isso, estão submetidos à falha que a mera existência do inconsciente flagra. Como causa da determinação do sujeito, o inconsciente, o non-sens inconsciente, emerge no simbólico como falha que deixa traços na forma-sujeito, ou seja, o ritual ideológico da identificação do sujeito com a forma-sujeito é, em sua essência, falho. Se o sujeito é dividido entre a ordem da consciência e a do inconsciente, sendo determinado em última análise por esta última, marcada, por sua vez, pelo desejo, as "ideologias dominadas" não podem estar fadadas a uma eterna repetição da ideologia dominante. Nas palavras de Pêcheux (1988), "não há dominação sem resistência" (p. 304).

Em 1982, Pêcheux assume esse pensamento em sua radicalidade, reconhecendo a existência de um real estranho à univocidade lógica que, não obstante, a determina. Esse real com o qual o sujeito só se depara, sem o apreender, é o que, do inconsciente, dá pistas do desejo e, consequentemente, da falha e da falta radicais que se instauram no processo mesmo do assujeitamento e fazem com que todo o sujeito, assim como todo o discurso, seja não-coincidente consigo mesmo. A equivocidade de toda evidência, então, passa a ser pensada como o sintoma de que algo não vai bem na homogeneidade da ideologia 
dominante, porquanto o sujeito é, sempre, sujeito do desejo. A evidência, dessa forma, é concebida por Pêcheux (1990) como furada e todo o discurso como suscetível de tornar-se outro, de deslizar, de deslocar-se e funcionar de forma a ameaçar os universos logicamente estáveis. Com isso, restaria o caro conceito de ilusão subjetiva intacto?

Žižek (1996), ao aproximar Marx de Lacan a partir do que este último defende em relação ao conceito de sintoma - o qual teria sido inventado por Marx, segundo um dos famosos aforismos lacanianos -, dá um passo adiante no entendimento da relação ideologia/inconsciente. Para tanto, relaciona os conceitos de sonho, em Freud, e de fetichismo da mercadoria, em Marx. Para o autor, a homologia existente entre os conceitos advindos de teorias heterogêneas entre si reside na forma. Žižek (1996) argumenta que, tanto no sonho, como no fetiche da mercadoria, há um terceiro elemento que atua não de forma a produzir sentidos a partir de algo oculto, mas de articulá-los. Nessa direção, pensa, o conteúdo manifesto do sonho - tanto quanto o pensamento latente - e a determinação do valor da mercadoria - em relação à quantidade de trabalho para sua produção - não são algo a ser "descoberto" ou "desvendado", já que em si são indetermináveis, mas a explicar por que assumiram aquela forma, respectivamente, a forma do sonho e a forma de valor da mercadoria.

Nessa linha argumentativa, defende que a troca de mercadorias só se dá a partir de uma dupla abstração: aquela do caráter mutável da mercadoria no ato de troca e a da sua concretude. Dessa maneira, o que Žižek chama de abstração real - isto é, aquela operada em relação à empiria, à forma como uma mercadoria assume o mesmo valor da mercadoria pela qual é trocada, independentemente do seu valor de uso permanece exterior ao pensamento, enquanto a primeira abstração, relativa ao caráter mutável da mercadoria - produz-se no interior do pensamento e, portanto, pode ser apreendida pelos sujeitos. $\mathrm{O}$ que resta desse raciocínio complexo é a permanência de algo fora do pensamento, produzido antes e independentemente, a abstração real, da qual o autor vai aproximar o conceito de ordem simbólica. Essa exterioridade é, por definição, estranha ao sujeito e, por isso, acarreta um desconhecimento essencial por parte dos sujeitos da troca. Nas palavras do autor:

(...) a efetividade social do processo de troca é um tipo de realidade que só é possível sob a condição de que os indivíduos que dela 
participam não estejam cientes de sua lógica própria, ou seja, é um tipo de realidade cuja própria consistência ontológica implica um certo não-conhecimento de seus participantes - se viéssemos a saber demais, a desvendar o verdadeiro funcionamento da realidade social, essa realidade se dissolveria (ŽıŽEK, 1996, p. 306).

Dessa forma, o desconhecimento é a condição mesma do funcionamento da troca. Analogamente, o desconhecimento de um desejo inconsciente que articula, dando forma ao sonho, o pensamento latente e o conteúdo manifesto, é condição para que essa articulação se dê; se o sujeito apreende a forma como o desejo inconsciente enreda-se no sonho, sua unidade subjetiva se desfaz. Eis, para o autor, o conceito de sintoma: algo que, em sua formação, implica, para manter sua consistência, um desconhecimento por parte do sujeito. Quando o sujeito atinge o cerne de seu sintoma, este se desfaz imediatamente: "o sujeito só pode gozar em seu sintoma na medida em que sua lógica lhe escapa - a medida do sucesso da interpretação do sintoma é, precisamente, sua dissolução" (ŽIŽEK, 1996, p. 306).

É a partir dessa constatação que Žižek funda o conceito de fantasia ideológica, o qual consiste na concepção da realidade como constitutivamente ilusória; a realidade, nessa perspectiva, é desde sempre falsa. Em outras palavras, a unidade lógica da realidade, sua totalidade, o universal ideológico em que se assenta é ilusório e não apenas isso: essa ilusão é condição para que a realidade tenha consistência, para que dê ao sujeito sua forma - forma essa que é a forma da autonomia. Essa realidade ilusória, no entanto, não pode ser "desvendada", pois a ilusão é condição de seu funcionamento, ou seja, tem efeito estrutural.

A fantasia ideológica, assim, é o elemento ilusório que estrutura a realidade social e determina o fazer dos sujeitos. Nesse sentido, não podemos dizer somente que o sujeito desconhece o caráter daquilo que o domina - se assim fosse, não seria difícil percebermos que somos dominados por uma série de regras e normas sociais, por exemplo, ou seja, que somos assujeitados a alguma ordem -, mas principalmente que desconhece o caráter ideológico de sua prática: "o que elas [as pessoas] não sabem é que sua própria realidade social, sua atividade, é guiada por uma 
ilusão, por uma inversão fetichista. O que desconsideram, o que desconhecem, não é a realidade, mas a ilusão que estrutura sua realidade, sua atividade social” (ŽIŽEK, 1996, p. 316).

Experimentamos, portanto, a realidade imaginária como verdadeira, embora sua constituição continue-nos inacessível, em sua dimensão real. Como na Psicanálise, a fantasia ideológica protege o sujeito do real das relações sociais. Apesar das críticas que Žižek faz a Althusser, acaba por complementar o que este último desenvolveu sobre as ideologias. Žižek (1992) defende que Althusser relaciona sua tese da interpelação ideológica somente ao lado da identificação, em seus aspectos simbólico e imaginário, sem considerar sua dimensão fantasística, ou seja, aquilo que remete ao desejo inconsciente, inassimilável por definição. É a dimensão do real que falta a Althusser, o que Pêcheux (1988) apreende ao designar o aspecto de nonsense da falha no ritual ideológico; o impossível a significar passa a ser entendido, então, como o ponto em que o assujeitamento se estilhaça.

À semelhança da fórmula lacaniana clássica segundo a qual a relação sexual não existe, Žižek (1992) formula a não existência das relações de classe, isto é, da mesma forma como a complementaridade entre os sexos é impossível, as classes em luta não são simétricas, não correspondendo uma ao seu oposto direto. A clivagem entre as classes em luta não é integrada à ordem simbólica e daí surge seu antagonismo, sempre dissimulado nas relações sociais:

Agora está clara a maneira como podemos utilizar essa noção de fantasia no campo da ideologia propriamente dita: também aqui, 'não existe relação de classe', a sociedade é sempre atravessada por uma clivagem antagônica que não pode ser integrada na ordem simbólica. E o que está em jogo na fantasia ideológico-social é construir uma visão da sociedade que exista, de uma sociedade que não seja antagonicamente dividida, uma sociedade em que a relação entre suas diferentes partes seja orgânica e complementar (ŽIŽEK, 1992, p. 123). 
Dessa forma, podemos dizer que o que é recalcado na realidade ilusória é justamente a relação assimétrica a que as classes em luta se submetem. As relações de dominação e servidão são, no capitalismo, recalcadas, assumindo a forma de livre relação entre sujeitos. Esse sintoma do edifício fantasístico da sociedade capitalista consiste em uma propriedade do sistema, sua condição mesma de existência e deriva no que Althusser chamou de assujeitamento, conceito ampliado por Žižek em seu apelo à Psicanálise. Assim, o assujeitamento em sua dimensão de fantasia ideológica é o real das sociedades capitalistas, o que sustenta a dupla ilusão de que Pêcheux (1988) nos fala: o sujeito se crê origem e controlador - fantasia primordial para que o indivíduo possa ser sujeito do que diz, enquanto não é nem um nem outro. O sujeito pode reconhecer sua submissão a uma dada ideologia e, mesmo, revoltar-se contra ela. O que o sujeito não pode conhecer, sob a ameaça de desintegração de sua própria realidade, é o mecanismo ideológico que o assujeita a priori, antes mesmo de sua identificação com esta ou aquela rede de saberes.

\section{A prática político-discursiva da intolerância}

O projeto de pesquisa Discurso de Ódio: mídias, redes e movimentos sociais, em desenvolvimento na UFPel desde 2016, tem se ocupado em construir um aparato teórico que seja capaz de suportar análises do que se chama comumente "discurso de ódio", em referência à forma como é chamada juridicamente a prática da violência discursiva. No entanto, a definição jurídica do discurso de ódio como aquele que é voltado contra minorias toma o sujeito como consciente e intencional. Em Análise de Discurso, sabemos, o sujeito é inconsciente e assujeitado à ideologia, o que torna inviável qualquer abordagem que parta de uma intencionalidade. Ainda, a definição de minorias como conjuntos identitários de gênero e raça, principalmente, parece-nos afetada pela ideologia dominante, já que toma como minorias parcelas consideráveis da população que, em uma dimensão quantitativa, não poderiam ser consideradas "minoritárias", embora sejam efetivamente parcelas da população que não têm lugar discursivo central nos saberes engendrados na/pela ideologia dominante ou, mesmo, nas instituições.

Nesse sentido, partimos da definição de violência desenvolvida por Žižek (2008), autor que trabalha na dupla perspectiva do Materialismo e da Psicanálise. Para o autor, existem dois tipos de violência: a subjetiva e a 
objetiva. A violência subjetiva, grosso modo, corresponde à violência física, aquela que percebemos imediatamente como uma forma de violência. Já a violência objetiva é dividida em dois subtipos: a violência sistêmica e a simbólica. Esta última diz respeito, em um primeiro momento, ao que identificamos, no senso comum, como discurso de ódio, ou seja, corresponde a atos verbalmente violentos. Além disso e principalmente, a violência simbólica funciona de forma a estabelecer o que Pêcheux (1990) chama de universos logicamente estáveis, nos quais, dizemos, alguns sujeitos tomam um lugar central e dominante e outros são produzidos como excedentes, isto é, como estranhos ao grupo social e, por isso, perigosos, já que ameaçam a homogeneidade ilusória de uma dada formação social. Por fim, a violência sistêmica é aquela produzida pelos próprios sistemas econômicos e políticos. No caso da formação social capitalista, essa violência especifica-se por significar a desigualdade social, a qual entendemos em relação à dissimetria entre as classes em luta, como "natural" e devida não ao funcionamento do sistema em si, mas às qualidades dos sujeitos que compõem a formação social. Nessa perspectiva, haveria sujeitos eficientes e, portanto, bem-sucedidos e detentores do capital, sujeitos médios que não deteriam o capital, mas conseguiriam "viver bem", e sujeitos ineficientes, aqueles que "merecem", de alguma forma, a miséria.

Os dois tipos de violência, assim como os subtipos da violência objetiva, não funcionam separadamente. Para Žižek (2008), a violência subjetiva é percebida sob um aparente grau zero de violência, enquanto ocorre, efetivamente, em decorrência da violência objetiva sistêmica e simbólica. Assim, a violência objetiva funciona como uma espécie de fundo ideológico sobre o qual se desenvolve a violência subjetiva, ou seja, as modalidades sistêmica, especialmente, e simbólica são, em última análise, a causa da violência física visível. Nesse sentido, seu funcionamento é, em maior ou menor grau, sutil, não sendo, na maior parte das vezes, percebido como violento, mas como "normal" e "natural", já que faz parte dos "universos semanticamente normais". Esse funcionamento mais ou menos invisível, que impõe sentidos aos sujeitos como se não houvesse outros sentidos possíveis, é justamente o que faz que, via esquecimento ideológico (Cf. PÊCHEUX, 1988), o sujeito não perceba a realidade como ilusória, bem como as relações de produção que a sustentam.

O discurso de ódio - que passaremos a designar como prática político-discursiva de intolerância - é, pois, definido, nos termos dos 
estudos que vimos desenvolvendo, como violência simbólica decorrente da violência sistêmica, mais especificamente, do recalcamento da luta de classes, o qual ressurge, por sua vez, como sintoma social. Esse sintoma pode se manifestar em processos discursivos percebidos como violentos ou intolerantes ou, mais sutilmente, na desqualificação e na (tentativa de) invisibilização de certos discursos, como é o caso do discurso feminista, por exemplo. A intolerância político-discursiva pode, inclusive, tomar a forma da tolerância liberal que, conforme Žižek (2008), é tão somente o "outro lado da moeda" da intolerância, já que igualmente mantém o outro/Outro a distância.

Definida, então, a prática político-discursiva da intolerância, podemos dizer que seu funcionamento invisível é tão ou mais eficiente do que seu funcionamento visível, na medida em que torna "normal" a exclusão e/ou desqualificação de dadas camadas da população ou, mesmo, de certos setores organizados da sociedade, como é o caso dos movimentos sociais, por exemplo. Como parte dos universos logicamente estabilizados, a intolerância é sistemática, ou seja, decorrente da estrutura sócioeconômica. Por isso, pode assumir formas que não se expressam diretamente no que é dito, Nesse sentido, convocamos o conceito de silêncio, tal como desenvolvido por Orlandi (1995).

Para a autora, todo o dizer relaciona-se com o não-dito. Em outras palavras, quando escolhemos dadas palavras em detrimento de outras, apagamos outros sentidos possíveis. Com isso, podemos dizer que o silêncio é necessário a qualquer prática discursiva, na medida em que tudo não pode ser dito (cf. MILNER, 2012). Orlandi (1995) defende que o silêncio é o fator que permite a movência dos sentidos, sendo, por isso, responsável, em última análise, pela existência mesma da significação. A palavra, para a autora, é movimento em torno desse princípio constitutivo da significação que é o silêncio. A esse silêncio que organiza os sentidos, Orlandi (1995) chama de "silêncio fundante", o qual se diferencia do nãodito. O não-dito diz respeito ao que a autora chama de silêncio local, que nos interessa particularmente no âmbito deste trabalho.

Partindo do pressuposto de que, sob as palavras, outras palavras significam, Orlandi (1995) desenvolve a noção de "silenciamento", como uma das modalidades do silêncio local. Este opera na interdição ao dizer e pode tomar formas bastante típicas e coercitivas, como é o caso da censura. No entanto, o silenciamento pode tomar formas menos autoritárias, embora igualmente coercitivas. É, naquilo que vimos 
desenvolvendo, o caso do discurso intolerante. $O$ silenciamento da intolerância parece ser uma característica do próprio discurso intolerante que assume, na contemporaneidade, a forma da tolerância. Nesse sentido, como já dissemos, a intolerância manifesta-se mais eficazmente no nãodito, naquilo que é omitido. Nossa hipótese, no presente trabalho é a de que esse discurso intolerante que assume a forma da tolerância, sendo, portanto, silenciado, é preenchido alhures, em outros discursos, especialmente naqueles que circulam fora da institucionalidade. É o que desenvolveremos, a partir de análises, na sequência.

Análise dos processos discursivos da intolerância em torno do Projeto de Lei "Escola sem Partido"

Em $\mathrm{AD}$, sabemos que não há procedimentos analíticos estabelecidos previamente. $\mathrm{O}$ analista trabalha no que Ernst-Pereira (2009) chamou de movimento pendular da teoria para o corpus e do corpus para a teoria. Por isso, construir a análise a partir da base teórica, sem recorrer à univocidade lógica, a qual implica aquele que interpreta como "senhor" absoluto, não é só tarefa difícil, mas um trabalho que envolve, como diz Pêcheux (1990), responsabilidade. Assim, frente à complexidade do corpus empírico, recorreremos, para a análise do PL Escola Sem Partido, primeiramente a Louis Althusser, uma vez que falar de escola sem pensá-la como um Aparelho Ideológico de Estado (AIE) comprometeria nossa análise e provavelmente impossibilitaria a visão da escola como lugar de reprodução das relações de produção e da ideologia, esta que para a $\mathrm{AD}$ é materializada na linguagem.

As evidências que o processo linguístico e histórico de designação da ideologia assume no senso comum podem ser agrupadas, para fins de análise, da seguinte forma: 1. Ideologia como um conjunto de ideias praticadas por grupos sociais; 2. Ideologia como uma distorção da realidade social; e 3. Ideologia como um conjunto de ideais ligados a organizações políticas, normalmente relacionadas à esquerda. A Ideologia, para a AD, é complexa, pois, como proposto por Althusser (1985), não tendo história nem fim, é um mecanismo que produz indivíduos como sujeitos, sujeitos de práticas sociais. Assim, a Ideologia tem existência material nos sujeitos e no discurso. Em outras palavras, na trilha de Althusser (1985) e Pêcheux (1988), o funcionamento da Ideologia dá-se nos sujeitos e na produção de evidências no discurso.

Assim, o processo de interpelação ideológica é indissociável do conceito de sujeito, este que é marcado pelo inconsciente, que é 
assujeitado e atravessado pela linguagem, pelo inconsciente e pela ideologia, Nas palavras de Leandro-Ferreira:

Ao ser constituído pela linguagem, o sujeito encontra nela sua morada e disso decorre uma marca do sujeito enquanto efeito de linguagem. Por outro lado, ao sofrer a determinação da ideologia, por via da interpelação, o sujeito se configura como assujeitado. E por ser também um sujeito do inconsciente, descontínuo por excelência e que se ordena por irrupções pontuais, esse sujeito se mostra como desejante (2017, p.5).

Ou seja, o sujeito é, sem o saber, submetido à ordem da ideologia e do inconsciente justamente por ser sujeito de linguagem e, como tal, sujeito desejante.

Como vimos dizendo, as ideologias consistem em um conjunto de práticas fundamentais à reprodução das relações de produção. $O$ Estado, enquanto instância de poder e coerção, precisa assegurar de alguma forma que seu papel seja cumprido e articula-se através dos aparelhos ideológicos de Estado (AIE) para garantir o papel repressivo do Estado. Tratando-se do AIE Escolar, o qual pode ser considerado o AIE dominante devido à obrigatoriedade da audiência dos alunos, percebe-se um esforço maior do Estado para garantir as condições políticas da reprodução das relações de produção. É então que o Estado, através do Aparelho Ideológico Jurídico, concebe leis que determinam a forma como os educadores podem (e devem) disciplinar os educandos a fim de que ingressem no "mercado de trabalho". Quando pensamos em disciplina, a partir do senso comum, relacionamo-la à obediência. A partir dessa observação, podemos dizer que o Projeto de lei Escola sem Partido, através de inúmeras proibições, visa garantir a reprodução das relações de produção dentro da escola.

O Estado articula-se para asseverar que os sujeitos obedeçam, que não tenham contato com saberes que possam vir a afetar a aparente estabilidade das relações de dominação, que reconheçam a necessidade da divisão do trabalho, bem como seu lugar nas relações de produção. 
O desenvolvimento das forças produtivas e o tipo de unidade historicamente constitutivo das forças produtivas num momento dado produzem esse resultado de que a força de trabalho deve ser (diversamente) qualificada e portanto reproduzida como tal (ALTHUSSER, 1985, p 57).

Reconhecendo o papel da escola no interior da formação social capitalista como o de qualificar a força de trabalho, percebemos que é através dela que se torna possível a reprodução das forças produtivas. Logo, a escola desempenha um papel fundamental na formação social que corresponde à formação de força de trabalho subserviente. Nesse sentido, o PL Escola sem Partido recorre à moral.

Lagazzi (1988), retomando as ideias de Foucault, descreve a moral como "um conjunto de regras e valores propostas aos indivíduos por intermédio de aparelhos prescritivos" (1988, p.46). O PL em questão, recorrendo à moral, funciona como uma ferramenta para garantir que o AIE Escolar não proponha atividades consideradas imorais, como é o caso das discussões provenientes da Teoria Feminista. Para garantir o apoio da população, estimula a ideia de que os pais terão autonomia para decidir qual é a educação moral a que seus filhos terão acesso. Dessa forma, o Estado garante que os sujeitos que frequentarem a escola serão sujeitados à moralidade, essa que para Lagazzi se coloca "como mais uma forma de conter o desejo do sujeito. A comunidade necessita zelar pelos bons costumes, mantendo os indivíduos enquadrados nos padrões morais escolhidos como seguros" (1988, p. 46).

Sendo assim, a escola, como todos os aparelhos ideológicos, regida pela necessidade da reprodução das relações de produção, não pode expor os estudantes a saberes morais considerados subversivos. Dessa maneira, há uma ideia ilusória de autonomia do sujeito gerada pelo assujeitamento ideológico, o que implica a ilusão de que os estudantes - e seus pais terão assegurada a exposição a saberes seguros à formação social capitalista, e não propriamente a saberes morais consoantes à convicção moral de seus pais, como prevê o texto do projeto.

Com a democratização do Estado Brasileiro após o Regime Militar, houve também um processo de democratização da aprendizagem, no qual as escolas passaram a debater diversos assuntos políticos e sociais. O sistema educacional brasileiro começou a dar relevância a saberes antes 
interditados, a procedimentos pedagógicos inclusivos e críticos. A partir dos anos 2000, as vagas nas universidades aumentaram, ainda que não suficientemente, permitindo, através de políticas públicas, o acesso de populações antes marginalizadas. Essa ampliação do acesso às universidades gerou, também, uma maior diversidade do conhecimento nelas produzido. Com isso, a circulação de saberes que ameaçam o funcionamento da formação social capitalista tornou-se visível e passou a ser visto por alguns setores da sociedade como ameaça.

Se consideramos que o Estado não é neutro, porquanto é o lugar de reprodução das relações de produção capitalistas, projetos como o Escola sem Partido funcionam como uma reação à mudança dos saberes que circulam na escola. Como proposto por Lagazzi (1988, p.16), “o Estado é o Estado-capitalista-jurídico e a divergência de interesses, a contraposição de direitos e deveres distintos, traz a necessidade da coerção". O projeto em questão funciona, assim, como um dos mecanismos de coerção jurídico-ideológica que visa determinar os saberes que podem e que devem circular nos meios escolares. Apesar de ainda não ter sido aprovado em âmbito federal ${ }^{35}$, o projeto faz circular um discurso que visa silenciar determinados saberes, como é o caso das discussões sobre gênero, e impor outros, notadamente saberes voltados à moral, historicamente relacionada às religiões cristãs.

Segundo Lagazzi (1988), existem conflitos entre o discurso jurídico, que funda o sujeito de direito - forma-sujeito dominante em nossa formação social - e o discurso religioso, já que a constituição do sujeito de direito deu-se através de um certo enfraquecimento do poder religioso que emanava da Igreja Católica. Assim, o atravessamento por saberes religiosos no PL Escola sem Partido causa estranhamento, já que, ao menos formalmente, a Igreja e o Estado são separados na formação social capitalista. Ao utilizar-se de questões morais e religiosas, especialmente no que concerne a temas como gênero e sexualidade, para constituir-se enquanto lei, o PL faz funcionar a contradição no interior mesmo da formação discursiva jurídica, o que pode ser exemplificado

${ }^{35} \mathrm{O}$ projeto já foi aprovado em diversos municípios tais como: Cricíuma - SC, Campo Grande - MS, Guarujá - SP, Jundiaí - SP, Lorena - SP, Santa Cruz do Monte Castelo - PR, São José do Rio Preto - SP, São Lourenço do Sul - RS, Picuí PB. 
pelo trecho seguinte: "Art. 30. São vedadas, em sala de aula, a prática de doutrinação política e ideológica bem como a veiculação de conteúdos ou a realização de atividades que possam estar em conflito com as convicções religiosas ou morais dos pais ou responsáveis pelos estudantes" (grifos nossos).

O estranhamento, para Ernst é:

Estratégia discursiva que expõe o conflito entre formações discursivas e consiste na apresentação de elementos intradiscursivos palavras, expressões e/ou orações - e interdiscursivos, da ordem do ex-cêntrico, isto é, daquilo que se situa fora do que está sendo dito, mas que incide na cadeia significante, marcando uma desordem no enunciado (2009, p. 3).

Em outras palavras, o estranhamento é índice da contradição, constitutiva do funcionamento das formações discursivas (Cf. COURTINE, 2009), as quais são heterogêneas, podendo, por isso, ser permeadas por saberes que lhes são externos. A contradição entre os saberes jurídicos do estado laico capitalista e os saberes religiosos que circulam no discurso sobre o Escola sem Partido funcionam como índices de sua constituição ideológica. No entanto, o atravessamento por saberes de ordem moral e religiosa não é explícito no projeto, mas silenciado de forma a ecoar em outro espaço, o espaço da campanha em prol do projeto, engendrada por grupos tais como o Movimento Brasil Livre, grupo conservador de direita que atua no Brasil.

Apesar de o texto do projeto, bem como de sua introdução, ser marcado pela falta de elementos diretamente relacionados à religião, é possível perceber índices de seu atravessamento pelo discurso moralreligioso, ao mesmo tempo em que esses saberes são colocados em oposição ao que o projeto designa como "prática de doutrinação política e ideológica”, como podemos perceber na sequência a seguir:

SD1: Diante dessa realidade - conhecida por experiência direta de todos os que passaram pelo sistema de ensino nos últimos 20 ou 30 anos -, entendemos que é necessário e 
O funcionamento da ideologia no projeto de lei Escola sem partido: uma leitura de práticas discursivas de intolerância | 91

urgente adotar medidas eficazes para prevenir a prática da doutrinação política $\mathrm{e}$ ideológica nas escolas, e a usurpação do direito dos pais a que seus filhos recebam a educação moral que esteja de acordo com suas próprias convicções (grifo nosso).

Com base na SD1, é possível perceber que o sujeito filia-se a uma dada rede de saberes na qual a ideologia é percebida como algo exterior ao sujeito, algo que é meio de "doutrinação" e, por isso, imposto aos estudantes. A relação estabelecida entre ideologia e doutrinação de forma a opor a primeira à "educação moral" faz ecoar sentidos relacionados à liberdade dos pais na educação dos filhos, ao mesmo tempo em que coloca a escola ao lado da doutrinação, designação associada, no senso comum, a uma autoridade inquestionável, como é o caso da concepção de doutrina, tal como compreendida no discurso religioso. No entanto, a natureza dessa doutrinação política e ideológica não é explícita no projeto. Estamos diante de uma falta, a qual, segundo Ernst (2009), consiste 1. na omissão, no fio do discurso, de palavras, expressões, estruturas sintáticas etc. que podem ou não ser recuperadas pelo sujeito; e 2. $\mathrm{Na}$ ausência de elementos do interdiscurso que seriam esperados num dado discurso.

$\mathrm{Na}$ SD em análise, a designação substantiva "ideologia”, bem como a designação "política", não aparece. No entanto, em seu lugar, surge "doutrinação política e ideológica". O deslocamento dos substantivos "política" e "ideologia" para os adjetivos "política" e "ideológica" recobre a falta de adjetivação em relação à ideologia e à política, ao mesmo tempo em que preenche o lugar do substantivo, dando a ele a falsa impressão de completude. Essa falta de adjetivação da ideologia e da política, recoberta pela organização do sintagma nominal, tem por efeito produzir uma concepção homogênea de política e ideologia. A partir dessa construção, que silencia de que política, mas principalmente, no âmbito deste trabalho, de que ideologia fala, o PL legitima-se frente à formação social, criando a falsa impressão de que: 1 . Toda ideologia é ruim; 2. A escola vem sendo "usada" para a formação de quadros políticos; 3 . A educação moral deve prevalecer em detrimento da formação política e ideológica. 
Essa lacuna, a qual Ernst (2009) entende encobrir pressupostos ideológicos ameaçadores, ao mesmo tempo em que faz crer que a ideologia é exterior ao sujeito, recobre a natureza necessariamente ideológica do discurso jurídico, o qual circula a partir do Aparelho Ideológico de Estado jurídico. Temos, então, a ideologia não mais apenas como exterior ao sujeito, mas como exterior também ao Estado e a seus aparelhos. Mas é o próprio texto que dá pistas de sua filiação também ideológica: a referência negativa a práticas de ensino nos últimos trinta anos, se retomarmos as condições de produção situacionais do projeto, remontam aos trinta anos do período democrático após a Ditadura Militar no país. Em outras palavras, o problema da educação brasileira surge com a abertura democrática.

O silêncio, entretanto, não apaga a memória sobre a educação na Ditadura Militar e os saberes que circulavam então, mas a faz circular como não dito local que é especificado em outro espaço, um espaço não institucional, que é o do site ${ }^{36}$ de propaganda do projeto. Nesse site, em 2017, figurava, como material de campanha, a paródia da canção "A banda", de Chico Buarque de Hollanda, intitulada "O bando", de autoria de Filipe Trielli e Danilo Gentilli. Nessa paródia, ressoam inúmeras ideias relacionadas à luta da esquerda no Brasil, uma vez que as condições de produção da versão original remetem à década de 1970 e acionam uma memória: o período em que o Brasil resistia ao regime militar. Dessa forma, percebemos que, ao utilizar a base musical para compor "O Bando", com letra manifestamente contrária aos ideais de esquerda, a paródia faz circularem efeitos de sentido que vêm preencher a falta analisada no texto do PL. Nessa perspectiva, torna-se evidente que tanto o material de apoio quanto o texto no PL propriamente dito funcionam como zona de embate ideológico, como podemos observar na sequência:

SD2: A marcha rubra se espalhou e a direita não viu

O Paulo Freire virou santo e fudeu (sic) com o Brasil

A Faculdade toda se enfeitou Pra me lobotomizar, me transformar num robô

${ }^{36}$ http://www.escolasempartido.org/ 
A referência à cor rubra, historicamente relacionada à esquerda e ao comunismo, opõe diretamente o que está em jogo no projeto de lei: esquerda $\mathrm{X}$ direita. $\mathrm{O}$ material de apoio do projeto recupera a memória a que está associado e à qual se filia: sendo também afetado pela ideologia, a lacuna do texto do projeto de lei, que silencia o adjetivo determinante de "política" e "ideologia", é preenchida: ideologia e política esquerdistas devem ser combatidas pela direita, associada à manutenção das relações de produção na formação social capitalista.

Ainda, o trecho analisado diz "O Paulo Freire virou santo e fudeu (sic) com o Brasil”, autor associado às práticas escolares críticas, tomadas como comunistas pelos defensores do Escola sem Partido. Por fim, surge uma referência às universidades, possivelmente públicas, que são, hoje, tomadas como lugares de "doutrinação comunista". O último verso da SD relaciona-se interdiscursivamente com a designação "doutrinação política e ideológica” presente no PL, já que, a partir dos saberes religiosos, entendemos a doutrina como um discurso autoritário advindo da figura divina e, por isso, inquestionável. Sob a égide da "marcha rubra", Paulo Freire e as universidades, lugares de produção de conhecimento, tornamse uma ameaça às escolas e à "educação moral" dos estudantes.

A ideologia, aqui, só existe nos movimentos de esquerda. $\mathrm{O}$ projeto de lei, proveniente do discurso jurídico, é, nessa perspectiva, dotado de "neutralidade", assim como a direita. Esse ideal de neutralidade, alinhado à direita, é, então, imposto à escola, sob a ilusão de que somente a esquerda é afetada pela ideologia e, consequentemente, capaz de "doutrinar", "lobotomizar" estudantes. A evidência a que se relaciona a designação "ideologia", nesse sentido, recobre a própria constituição ideológica do projeto, assim como de seu material de campanha, desqualificando toda e qualquer prática considerada de esquerda. Vale lembrar que as políticas de gênero são, no âmbito do projeto, consideradas prejudiciais à "educação moral” e, portanto, prática de doutrinação política e ideológica. De esquerda.

\section{Considerações finais}

A prática político-discursiva da intolerância assume, na sociedade capitalista pós-industrial, afetada pela ilusão de autonomia, formas sutis, como é o caso do texto do Projeto de Lei Escola sem partido. No entanto, no caso em análise, a violência manifesta-se claramente em espaços não institucionais, promovendo a desqualificação de práticas consideradas 
subversivas e, via de regra, alinhadas à esquerda. A ideologia, nesse ponto, só é atributo do outro, desse outro que ameaça a unidade da formação social.

A designação "ideologia", tal como apresentada no PL, funciona como uma evidência: todo mundo sabe o que é ideologia e, mais, todo mundo sabe o quanto é perigosa e deve, por isso, permanecer exterior ao sujeito e às práticas pedagógicas. No entanto, essa evidência funciona como sintoma do funcionamento ideológico real: ao acreditar ser possível controlar a filiação ou não a uma ou outra ideologia, o sujeito desconhece sua própria constituição pela ideologia, o que faz com que ela funcione plenamente.

A ideologia, na concepção com que vimos trabalhando, funciona como elemento estruturador da realidade social; o que o sujeito percebe como real é, na verdade, construto ideológico que lhe dá a ilusão de autonomia e liberdade. Essa ilusão, própria da formação social capitalista, escapa ao sujeito, na medida em que é ela que lhe fornece a impressão de realidade e lhe dá consistência subjetiva. Assim, o sujeito desconhece o caráter ideológico de suas práticas sociais.

O discurso jurídico, determinado no e pelo Aparelho Ideológico de Estado jurídico, apesar de produzido por sujeitos, toma, então, a forma da neutralidade e, com isso, legitima-se frente à formação social como aquilo que deve ser, isto é, como algo exterior ao sujeito e destituído de funcionamento ideológico. $O$ caso do projeto aqui analisado, esse discurso jurídico, atravessado pelo discurso moral-religioso, aponta a ideologia, assim como a política, como algo negativo e ameaçador, que, por isso, deve ser mantido à distância das escolas. Ora, se a ideologia dominante na formação social capitalista é, também, de natureza capitalista, ela não é percebida como tal, mas como uma espécie de grau zero ideológico. Logo, ideologia é tudo que se opõe ao dominante, pois percebido como algo que ameaça a univocidade lógica (Cf. PÊCHEUX, 1990), tão cara à consistência dos sujeitos sociais.

O material de campanha do Movimento Escola sem Partido trai, nesse sentido, a evidência ideológica construída no PL, pois, ao dizer "a marcha rubra se espalhou e a direita não viu”, recupera discursivamente, sem o saber, o antagonismo de classe de que fala Žižek (1996), este gerado pela não integração da dissimetria da luta de classes na ordem simbólica. Ao opor "marcha rubra" e "direita", restitui, como num lapso, a oposição ausente no texto do PL: trata-se, aqui, de uma luta entre os dois opostos 
do espectro das ideologias particulares, que correspondem às duas classes em posição antagônica.

\section{REFERÊNCIAS}

ALTHUSSER, Louis. Aparelhos Ideológicos de Estado: notas sobre os aparelhos ideológicos de estado. 10a Ed. Trad. Walter J. Evangelista e Ma Laura V. de Castro. Rio de Janeiro: Ed. Graal, 1985.

COURTINE, Jean-Jacques. Análise do discurso político: o discurso comunista endereçado aos cristãos. [trad.] Cristina de Campos Velho Birck [et al.] São Carlos: EdUFSCar, 2009.

ERNST-PEREIRA, Aracy. A falta, o excesso e o estranhamento na constituição/interpretação do corpus discursivo. Disponível em:

http://anaisdosead.com.br/4SEAD/SIMPOSIOS/AracyErnstPereira.pdf, consulta em: 30 de maio de 2015.

FERREIRA, Maria Cristina L. A trama enfática do sujeito. Disponível em:

http://anaisdosead.com.br/2SEAD/SIMPOSIOS/MariaCristinaL eandroFerreira.pdf, consulta em: junho de 2017.

GUIMARÃES, Eduardo. Semântica do acontecimento: um estudo enunciativo da designação. 2a Ed. Campinas, SP: Pontes, 2005.

LAGAZZI, Suzy. O desafio de dizer não. 1a Ed. São Paulo: Pontes, 1988.

ORLANDI, Eni. As formas do silêncio: no movimento dos sentidos. 3. ed.. Campinas: UNICAMP, 1995.

MILNER, Jean-Claude. O amor da língua. Trad. Ângela Cristina Jesuíno. Porto Alegre: Artes Médicas, 2012.

PÊCHEUX, Michel. O Discurso: estrutura ou acontecimento. Trad. Eni Orlandi. Campinas: Pontes, 1990.

- Semântica e Discurso: uma crítica à afirmação do óbvio. Trad. Eni Orlandi et al. Campinas : Editora da Unicamp, 1988.

ŽIŽEK, Slavoj. Eles não sabem o que fazem. O sublime objeto da ideologia. Rio de Janeiro: Zahar Editor, 1992.

. Como Marx inventou o sintoma. In: ŽIŽEK, Slavoj (Org.). Um mapa da Ideologia. Trad. Vera Ribeiro. Rio de Janeiro: Contraponto, 1996. 
96 |Janaina Cardoso Brum e Jenifer Dias

. Um mapa da Ideologia. Trad. Vera Ribeiro. Rio de Janeiro: Contraponto, 1996.

- Violência. Trad. Miguel Serras Pereira. São Paulo: Boitempo, 2008.

Recebido em: 26/11/2018

Aceito em: 02/12/2018 